УДК 902.4

ББК 63.4

DOI 10.31554/2222-9175-2019-35-10-161-165

Р. В. Аавыдов

ОПЫТ ПРИМЕНЕНИЯ ФОТОГРАММЕТРИИ

КАК СПОСОБА ЦИФРОВОЙ ФИКСАЦИИ ИНФОРМАЦИИ В ПОАЕВЫХ УСАОВИЯХ

Представлены результаты использования 3D-фиксации методом фотограмметрии, выполненной в ходе изучения погребального памятника таштыкской культуры Тесинский Залив-3, находящегося в аварийном состоянии. При помощи фотоаппарата Nikon, программного обеспечения Agisoft PhotoScan и Geomagic Wrap построены виртуальные модели двух могил, погребения в которых содержат информацию о разных типах погребального обряда.

Ключевые слова: погребальный обряд, полевая археология, таштыкская культура, фотограмметрия, Южная Сибирь, 3D-моделирование.

R. V. Davydov

\title{
EXPERIENCE OF USING OF PHOTOGRAMMETRY AS A METHOD OF DIGITAL FIXING INFORMATION IN FIELD CONDITIONS
}

The author presents the results of using 3D-fixation by photogrammetry, which was carried out in the course of researching the burial site of Tashtyk culture Tesinsky Zaliv-3, which is in disrepair. Using the Nikon camera and Agisoft PhotoScan and Geomagic Wrap software, virtual models of two graves were built. The burials in this graves contain information about different types of burial rites.

Keywords: burial rite, field archeology, Tashtyk culture, photogrammetry, South Siberia, 3D modeling.

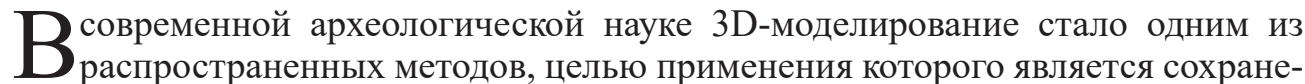
ние, сравнение, демонстрация и обмен наиболее полной визуальной информацией об объекте. Оно является важной частью исследований и программ по сохранению и трансляции историко-культурного наследия.

Распространено применение различных 3D-технологий при фиксации и реконструкции первоначального облика мобильных артефактов [Белавин, Вострокнутов 2013; Казаков 2016; Казаков и др. 2016; Пушкарев, Вавулин 2013]. Также проводятся съемка и 3D-моделирование нетранспортабельных объектов в полевых условиях. Наиболее распространено моделирование петроглифов с целью подробной фиксации скальной поверхности для сохранения изображений и их детального обследования, поскольку некоторые детали рисунка и следы инструментов, изучаемые при

ДАВЫДОВ Роман Вячеславович - инженер-исследователь лаборатории гуманитарных исследований Государственного бюджетного образовательного учреждения высшего образования «Новосибирский государственный университет», магистрант (Новосибирск, Россия). E-mail: puer-viro@mail.ru. 
трасологическом анализе, обнаруживаются только на 3D-моделях. Сканируются или фотографируются как целые композиции, так и отдельные участки с большим увеличением [Дэвлет, Ларскин 2015: рис. 1, 2; Зоткина 2014]. В последние годы осуществляется сканирование пещерных памятников [Казаков 2016: 50; Леонов и др. 2014]. Производится также моделирование погребений, что позволяет тщательнее сохранить информацию, сравнить погребальные конструкции, реконструировать их изначальный вид [Бородовский, Олещак 2015; Зайцева 2014].

В полевом сезоне 2018 г. Красноярским археологическим отрядом Лаборатории гуманитарных исследований Новосибирского государственного университета с участием бакалавров и магистрантов кафедры археологии и этнографии Гуманитарного института НГУ, совместно с сотрудниками Института археологии и этнографии СО РАН, студентами и преподавателями Новокузнецкого филиала Кемеровского государственного университета и Тюменского индустриального университета (ТИУ) проводились работы по изучению грунтового могильника таштыкской культуры Тесинский Залив-3 (Боградский р-н Республики Хакасия).

Памятник находится в аварийном состоянии. Он расположен на берегу Красноярского водохранилища, на обрыве, который ежегодно размывается. Всего в границах могильника зафиксирован 81 объект, в т. ч. 80 западин могильных ям [Митько и др. 2017: 356]. Ближайшие к берегу погребения находятся вплотную к обрыву. Их изучение является приоритетным направлением работ на памятнике. При обследовании части памятника, находящейся в критическом состоянии, используется комплекс естественнонаучных методов, включая магнитометрическое картирование (выполнено студентами геолого-геофизического факультета НГУ и студентами ТИУ под руководством к.г.-м.н. А. Н. Василевского) и 3D-моделирование важных объектов, к которым в первую очередь относятся погребения, методом фотограмметрии [Митько и др. 2018: 286].

Для съемки было выбрано две аварийные могилы (могила 2А и могила 9), погребения в которых являются наглядными примерами двух разных погребальных обрядов, связанных с полом умершего. Таштыкская культура, существовавшая на территории Хакасско-Минусинской котловины в течение длительного срока (IVII вв. н. э.), характеризуется большим разнообразием погребального обряда (кремация, ингумация, захоронения в грунтовых могилах, в склепах, под каменными выкладками) [Митько, Николаева 2016: 99, 103]. Уточнение хронологических рамок бытования того или иного типа обряда, его взаимосвязи с половозрастными и социальными характеристиками умершего, возможных вариаций, является в настоящее время актуальным направлением исследований. В связи с этим важное значение имеет детальная фиксация погребений как единого комплекса с возможностью их дальнейшей демонстрации и сопоставления.

Первая зафиксированная могила (могила 2А) была обнаружена при обследовании берега по торчащим из обрыва костям. В могиле, на глубине 1,1 м от современной дневной поверхности, находилось погребение по обряду трупоположения. Оно оказалось частично разрушено - сохранилась только верхняя часть скелета, в то время как кости нижней были вымыты водой и выявлены ниже в обрыве в беспорядке. Обследование черепа показало, что это была молодая женщина.

Данная могила - первая из обнаруженных на памятнике, сохранившаяся неразграбленной, благодаря чему все предметы уцелевшей части оказались in situ. На черепе, по бокам нижней челюсти обнаружены фрагменты гипсовой маски. На темени лежали роговые шпильки с молоточковидными окончаниями. Они использовались для фиксации прически. В верхней части туловища зафиксированы бусины из различных материалов (всего 7 шт., в ходе промывки земли из-под черепа найдено 
еще 7 шт.). При расчистке костяка установлена особенность погребального обряда: череп был слегка приподнят, в стороне от него и чуть выше находились два шейных позвонка [Митько и др. 2018: 286-287].

Таким образом, сохранившаяся часть могилы 2 А представляла собой сложный комплекс, уцелевший в непотревоженном состоянии и содержащий информацию о различных аспектах погребального обряда и материальной культуры таштыкского населения. Для сохранения максимально точной информации о нем была выполнена фиксация методом фотограмметрии.

Второй объект, который был отснят для последующего построения 3D-модели могила 9. Она имела глубину 1,9 м и представляла собой сруб размерами 2,35×1,6 м, высотой, - в один венец, сложенный из бревен. Конструкция имела перекрытие из бересты и бревен и берестяной пол. На уровне пола найдены кальцинированные кости, указывающие на то, что это было погребение мужчины. Могила была разграблена, из-за чего обнаружено два фрагмента керамики [Там же: 287].

Внутримогильная конструкция представляет собой яркий пример срубов, фиксируемых в грунтовых могилах таштыкской культуры, датируемых I-IV вв. н. э. [Вадецкая 1999: 17]. В связи с этим было принято решение произвести фиксацию конструкции методом фотограмметрии. Съемка велась на двух уровнях - на уровне остатков перекрытия и после расчистки сруба.

Расположение могил в обрыве позволило выполнить детальную съемку без использования дополнительной подсветки. Фотографирование могилы 2 А было осложнено тем, что оно проводилось в солнечный день, в связи с чем часть объекта оказалась в тени, а часть освещена более ярко.

При съемке могилы 9 в обоих случаях была пасмурная погода, благодаря чему она оказалась освещена равномерно. Отсутствие солнца не оказало негативного влияния на качество итоговых моделей, поскольку в погребении не было мелких деталей. Осложнение вызвало близкое расположение сруба к стенке могильной ямы, в связи с чем часть внешней стороны стенки не была отснята так же подробно, как остальная конструкция, и кадры ее съемки имели другое фокусное расстояние.

Полученные методом фотограмметрии модели имеют разрешение до 5 мм при съемке в 40 кадров [Зайцева 2014: 277]. Для лучшей детализации погребений количество фотографий было существенно увеличено.Съемка выполнена фотоаппаратом Nikon D3200 с объективом EF-S 18-55mm f/3.5-5.6G. При фиксации могилы 2A произведено 140 снимков (по 5 окружностям). В ходе съемки могилы 9 сделано 184 (на уровне перекрытия) и 229 (на уровне расчищенного сруба) фотографий (по 8 окружностям). Модели построены в программе Agisoft PhotoScan (с целью снижения итогового размера модели выбрано среднее качество выравнивания фотографий и плотного облака точек) и обработаны в программе Geomagic Wrap. Итоговые модели имели достаточное разрешение, позволяющее, например, увидеть месторасположение, цвет и форму бусин в могиле 2 А (их размер не превышает 8 мм).

В ходе дальнейших работ на могильнике Тесинский Залив-3 предполагается создание цифровой базы данных, содержащей серию моделей погребальных конструкций с сопроводительным инвентарем. Их сопоставление позволит наглядно показать сходства и различия в устройстве внутримогильных срубов и особенности расположения инвентаря. Ведутся работы по виртуальной реконструкции первоначального облика сруба из могилы 9. Модели используются как демонстрационный материал, планируется их размещение в виртуальном музее, функционирующем на базе Новосибирского государственного университета в режиме свободного доступа (https://3d.nsu.ru/ru/category/1). 
Исследование проведено в рамках государственного задания в сфере научной деятельности (проект № 33.5677.2017/8.9).

\section{Һитература}

Белавин А. М. К вопросу об использовании цифровых и 3D-технологий при работе с археологическими материалами / А. М. Белавин, А. В. Вострокнутов // Археология Севера России: от эпохи железа до Российской империи. - Екатеринбург; Сургут: Магеллан, 2013. C. 285-287.

Бородовский А. П. 3D-моделирование каменного погребального ящика эпохи раннего железа Горного Алтая / А. П. Бородовский, Л. Олещак // Теория и практика археологических исследований. - 2015. - № 2(12). - С. 93-98.

Вадеикая Э. Б. Таштыкская эпоха в древней истории Сибири / Э. Б. Вадецкая. - СПб.: Петербургское Востоковедение, 1999. - 440 с.

Дэвлет Е. Г. Петроглифы Хабаровского края: результаты мониторинга последствий паводка в 2013 г. на Амуре и Уссури / Е. Г. Дэвлет, А. Р. Ларскин // Археология, этнография и антропология Евразии. - 2015. - Т. 43. - № 4. - С. 94-106.

Зайцева O. B. 3D-фиксация и визуализация результатов археологических раскопок: сравнение методик трехмерного сканирования и неземной фотограмметрии / О. В. Зайцева // Труды IV (XX) Всероссийского археологического съезда в Казани. T. IV. - Казань: Отечество, 2014. - С. 300-302.

Зоткина Л. В. Возможности фиксации петроглифов для трасологического изучения (к историографии вопроса) / Л. В. Зоткина // Вестник Новосибирского гос. ун-та. Серия: История, филология. - 2014. - Т. 13. - № 3: Археология и этнография. - С. 16-26.

Казаков В. В. Применение информационных технологий в задачах Лаборатории мультидисциплинарных исследований первобытного искусства Евразии НГУ / В. В. Казаков // Вестник Новосибирского гос. ун-та. Серия: Информационные технологии. - 2016. - Т. 14. № 4. - С. 50-57.

Казаков B. B. Трехмерное сканирование музейных экспонатов по технологии структурированного подсвета / В. В. Казаков, В. С. Ковалев, К. Б. Жумадилов // Universum Humanitarium. - 2016. - № 2(3). - С. 58-64.

Леонов А. В. Создание виртуальной 3D-модели Денисовой пещеры / А. В. Леонов, М. Н. Аникушкин, А. Е. Бобков, И. В. Рысь, М. Б. Козликин, М. В. Шуньков, А. П. Деревянко, Ю. М. Батурин // Археология, этнография и антропология Евразии. - 2014. - Т. 59. - № 3. C. 14-20.

Митько О. А. Особенности погребального обряда таштыкского населения (по данным антропологического анализа захоронений под каменными выкладками на могильнике Маркелов Мыс II) / О. А. Митько, Т. А. Николаева // Вестник Томского государственного университета. История. - 2016. - № 6(44). - С. 98-105.

Митько О. А. Начало изучения таштыкского грунтового могильника Тесинский Залив-3 (Богорадский район, Республика Хакасия) / О. А. Митько, Ю. С. Худяков, С. Г. Скобелев, А. И. Поселянин, И. С. Половников // Проблемы археологии, этнографии, антропологии Сибири и сопредельных территорий. - 2017. - Т. ХХІІІ. - С. 354-357.

Митько O. А. Могильник таштыкской культуры Тесинский Залив-3: итоги полевого сезона 2018 года / О. А. Митько, С. Г. Скобелев, Ю. В. Ширин, В. С. Зубков, А. И. Поселянин, Р. В. Давыдов, Е. А. Журавлева, И. С. Половников, Р. Л. Собинов // Проблемы археологии, этнографии, антропологии Сибири и сопредельных территорий. - 2018. - T. XXIV. C. 285-289.

Пушкарев A. А. Возможности трехмерного отображения археологических артефактов в научной и музейной презентации / А. А. Пушкарев, М. В. Вавулин // Археология Севера России: от эпохи железа до Российской империи. - Екатеринбург; Сургут: Магеллан, 2013. C. 288-291. 


\section{References}

Belavin A. M. K voprosu ob ispol'zovanii cifrovyh i 3D-tekhnologij pri rabote s arheologicheskimi materialami / A. M. Belavin, A. V. Vostroknutov // Arheologiya Severa Rossii: ot epohi zheleza do Rossijskoj imperii. - Ekaterinburg; Surgut: Magellan, 2013. - S. 285-287.

Borodovskij A. P. 3D-modelirovanie kamennogo pogrebal'nogo yashchika epohi rannego zheleza Gornogo Altaya / A. P. Borodovskij, L. Oleshchak // Teoriya i praktika arheologicheskih issledovanij. - 2015. - № 2(12). - S. 93-98.

Vadeckaya E. B. Tashtykskaya epoha v drevnej istorii Sibiri / E. B. Vadeckaya. - SPb.: Peterburgskoe Vostokovedenie, 1999. - $440 \mathrm{~s}$.

Devlet E. G. Petroglify Habarovskogo kraya: rezul'taty monitoringa posledstvij pavodka v 2013 g. na Amure i Ussuri / E. G. Devlet, A. R. Larskin // Arheologiya, etnografiya i antropologiya Evrazii. - 2015. - T. 43. - № 4. - S. 94-106.

Zajceva $O$. V. 3D-fiksaciya i vizualizaciya rezul'tatov arheologicheskih raskopok: sravnenie metodik trekhmernogo skanirovaniya i nezemnoj fotogrammetrii / O. V. Zajceva // Trudy IV (XX) Vserossijskogo arheologicheskogo s"ezda v Kazani. T. IV. - Kazan': Otechestvo, 2014. S. 300-302.

Zotkina L. V. Vozmozhnosti fiksacii petroglifov dlya trasologicheskogo izucheniya (k istoriografii voprosa) / L. V. Zotkina // Vestnik Novosibirskogo gos. un-ta. Seriya: Istoriya, filologiya. - 2014. - T. 13. - № 3: Arheologiya i etnografiya. - S. 16-26.

Kazakov $V . \quad V$. Primenenie informacionnyh tekhnologij $\mathrm{v}$ zadachah Laboratorii mul'tidisciplinarnyh issledovanij pervobytnogo iskusstva Evrazii NGU / V. V. Kazakov // Vestnik Novosibirskogo gos. un-ta. Seriya: Informacionnye tekhnologii. - 2016. - T. 14. - № 4. - S. 50-57.

Kazakov $V$. V. Trekhmernoe skanirovanie muzejnyh eksponatov po tekhnologii strukturirovannogo podsveta / V. V. Kazakov, V. S. Kovalev, K. B. Zhumadilov // Universum Humanitarium. 2016. - № 2(3). - S. 58-64.

Leonov A. V. Sozdanie virtual'noj 3D-modeli Denisovoj peshchery / A. V. Leonov, M. N. Anikushkin, A. E. Bobkov, I. V. Rys', M. B. Kozlikin, M. V. Shun'kov, A. P. Derevyanko, Yu. M. Baturin // Arheologiya, etnografiya i antropologiya Evrazii. - 2014. - T. 59. - № 3. - S. 14-20.

Mit'ko O. A. Osobennosti pogrebal'nogo obryada tashtykskogo naseleniya (po dannym antropologicheskogo analiza zahoronenij pod kamennymi vykladkami na mogil'nike Markelov Mys II) / O. A. Mit'ko, T. A. Nikolaeva // Vestnik Tomskogo gosudarstvennogo universiteta. Istoriya. - 2016. - № 6(44). - S. 98-105.

Mit'ko O. A. Nachalo izucheniya tashtykskogo gruntovogo mogil'nika Tesinskij Zaliv-3 (Bogoradskij rajon, Respublika Hakasiya) / O. A. Mit'ko, Yu. S. Hudyakov, S. G. Skobelev, A. I. Poselyanin, I. S. Polovnikov // Problemy arheologii, etnografii, antropologii Sibiri i sopredel'nyh territorij. - 2017. - T. XXIII. - S. 354-357.

Mit'ko O. A. Mogil'nik tashtykskoj kul'tury Tesinskij Zaliv-3: itogi polevogo sezona 2018 goda / O. A. Mit'ko, S. G. Skobelev, Yu. V. Shirin, V. S. Zubkov, A. I. Poselyanin, R. V. Davydov, E. A. Zhuravleva, I. S. Polovnikov, R. L. Sobinov // Problemy arheologii, etnografii, antropologii Sibiri i sopredel'nyh territorij. - 2018. - T. XXIV. - S. 285-289.

Pushkarev A. A. Vozmozhnosti trekhmernogo otobrazheniya arheologicheskih artefaktov v nauchnoj i muzejnoj prezentacii / A. A. Pushkarev, M. V. Vavulin // Arheologiya Severa Rossii: ot epohi zheleza do Rossijskoj imperii. - Ekaterinburg; Surgut: Magellan, 2013. - S. 288-291. 